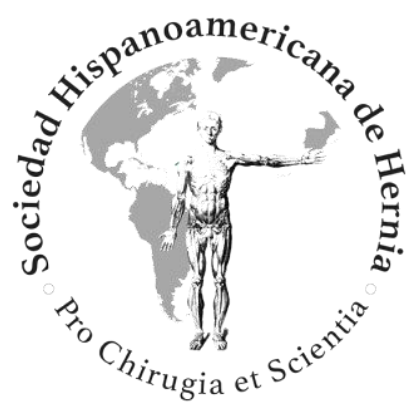

Comillas, uso correcto

\title{
Quotes, correct usage
}




\section{CARTA AL DIRECTOR}

\section{Comillas, uso correcto}

\section{Sr. Director:}

El uso de las comillas es uno de los aspectos de la escritura que pasa más desapercibido y que, a pesar de su extendido mal uso, menos dudas genera.

En español se usan diferentes tipos de comillas: las angulares, también llamadas latinas o españolas ( «»), las inglesas (") y las simples ("). El uso de las inglesas es el que está más ampliamente aceptado, debido, entre otras causas, a una simple cuestión tecnológica: su fácil acceso en los teclados de las máquinas de escribir y de los ordenadores, primero, y en los de los móviles, después. Para llegar a las comillas españolas hay que entrar en cuadros secundarios que ralentizan la escritura (como el de «Símbolos» en Word, por ejemplo) y que, en la mayoría de los casos, ni siquiera resultan intuitivos.

Pero tal y como recoge el Diccionario panhispánico de dudas ${ }^{1}$, en los textos impresos «se recomienda utilizar en primera instancia las comillas angulares, reservando los otros tipos para cuando deban entrecomillarse partes de un texto ya entrecomillado. En este caso, las comillas simples se emplearían en último lugar», como en el siguiente ejemplo: «El cirujano explicó: “No hemos encontrado diferencia significativa en la variable 'tiempo operatorio' para hernias primarias frente a recidivadas" $\gg^{2}$.

Por último, cabe recordar que las comillas inglesas y las simples se escriben «en la parta alta del renglón, mientras que las angulares se escriben centradas» ${ }^{1}$.

\section{BIBLIOGRAFÍA}


1. Disponible en: https://www.rae.es/dpd/comillas

2. Mariano Palmisano $E$, Blanco $M$. Hernioplastia inguinal transabdominal preperitoneal (TAPP) sin fijación de la malla. Experiencia inicial a corto plazo. Rev Hispanoam Hernia. 2020;8(1):19-24.

Jorge Megías

revistas@grupoaran.com 